\title{
Partial Chemical Characterization of Immunomodulatory Polysaccharides from Plantago palmata Hook. f. s. Leaves
}

\author{
Gabriel Biringanine, ${ }^{1}$ Moustapha Ouedraogo, ${ }^{2}$ Bernard Vray, ${ }^{3}$ \\ Anne Berit Samuelsen, ${ }^{4}$ and Pierre Duez ${ }^{1}$ \\ ${ }^{1}$ Laboratoire de Pharmacognosie, de Bromatologie, et de Nutrition Humaine, Faculté de Pharmacie, Université Libre de Bruxelles \\ (ULB), Campus Plaine CP 205/9, Boulevard du Triomphe, 1050 Bruxelles, Belgium \\ ${ }^{2}$ Laboratoire de Pharmacologie et de Toxicologie, Unité de Formation et de Recherche en Sciences de la Santé, Université de \\ Ouagadougou, Ouagadougou 03, Burkina Faso \\ ${ }^{3}$ Laboratoire d'Immunologie Expérimentale, Faculté de Médecine, Université Libre de Bruxelles (ULB), Campus Erasme, Route de \\ Lennik, 1070 Bruxelles, Belgium \\ ${ }^{4}$ Department of Pharmaceutical Chemistry-Pharmacognosy, School of Pharmacy, University of Oslo, P.O. Box 1068, Blindern, \\ 0316 Oslo, Norway
}

Correspondence should be addressed to Pierre Duez,pduez@ulb.ac.be

Received 30 May 2012; Accepted 25 June 2012

Academic Editor: Jianjun Li

Copyright ( $\odot 2012$ Gabriel Biringanine et al. This is an open access article distributed under the Creative Commons Attribution License, which permits unrestricted use, distribution, and reproduction in any medium, provided the original work is properly cited.

\begin{abstract}
A previous work on Plantago palmata polysaccharides (PS) attributed immunomodulatory properties of leaves to a polysaccharide fraction (PS50) that stimulated NO and TNF- $\alpha$ production by interferon gamma- (IFN- $\gamma$-) activated macrophages. The present work aims to elucidate the chemical structure of these immunomodulatory polysaccharides. Size exclusion chromatography showed that the active polymers present an active fraction with a very high molecular weight (about $1200 \mathrm{kDa}$ ). These polysaccharides are pectic in nature, with a predominantly unbranched galacturonan domain and with a domain bearing side chains that consist of highly branched arabinan, galactan, and/or arabinogalactan. Comparatively to the well-known Plantago major biologically active PS, Plantago palmata PS50 contained less arabinogalactan-proteins (AGPs) and had a different composition in glucose, galactose, and galacturonic acid. DNA contamination of the polysaccharide was estimated at about $0.04 \%$, a concentration much lower than those reported immunomodulatory in hyaluronic acid preparations ( 3 to $15 \%)$. Therefore, the eventuality of a contaminating DNA-mediated biological activity could be ruled out.
\end{abstract}

\section{Introduction}

Plantago palmata grows in the humid mountain regions of intertropical Africa at 1800 to $3000 \mathrm{~m} \mathrm{[1]} \mathrm{and} \mathrm{is} \mathrm{widely}$ used in traditional medicine in Burundi, Rwanda and South Kivu (Democratic Republic of Congo). Its leaves are often used as herbal remedies in the treatment of a number of diseases such as wounds, hepatitis, parasitic or infectious diseases, and pregnancy, and lactation troubles. They are also used for the improvement of health after disease $[2,3]$. A survey of the literature indicates a certain convergence between these medicinal uses (antibacterial, antifungal, antiviral and, immunomodulatory) and those of other Plantago species [4-11]. This led us to investigate three groups of Plantago metabolites possibly related to these traditional uses and biological activities, that is, iridoids, phenylethanoid glycosides and polysaccharides $[3,12]$.

We previously showed that Plantago palmata leaves (i) contain appreciable amounts of iridoids and phenylethanoid glycosides, with aucubin and acteoside as major compounds [2]; (ii) present immunomodulatory properties, which could be attributed to polysaccharides (PS) [3].The effects of crude extracts and fractions obtained by high performance liquid chromatography/size exclusion chromatography (SEC) were investigated by the measurement of nitric oxide (NO), tumor necrosis factor-alpha (TNF- $\alpha$ ), and interleukin-10 (IL-10) 
production using interferon gamma- (IFN- $\gamma_{-}$) activated macrophages and nonactivated macrophages as control. IFN- $\gamma$-activation of J774 cell line macrophages synergized with a raw $50^{\circ} \mathrm{C}$ aqueous extract from leaves (PS50) and one of its fractions obtained by SEC (fraction F2) to produce both NO and TNF- $\alpha$, but not IL-10. Eventual contamination of PS extracts and fractions by lipopolysaccharide (LPS) was ruled out by showing the same pattern of response on peritoneal macrophages harvested from $\mathrm{C} 3 \mathrm{H} / \mathrm{Hej}$ mice, a strain known to be a very low responder to LPS.

Due to their potential biological activities, such as antioxidant, antiulcer, hepatoprotective, antitumor, and immunostimulatory effects, polysaccharides from natural sources have attracted more attention in recent years [1317]. To the best of our knowledge, primary structures, spatial shapes, and functions of PS are intimately related. Therefore as a prerequisite to better understand immunomodulatory activities of $P$. palmata polysaccharides, but also to develop parameters for quality control, the present work aims to investigate their primary chemical structures.

\section{Experimental}

2.1. Plant Material and Polysaccharides (PS) Extraction. Plantago palmata seeds were harvested in the Democratic Republic of Congo and grown in a greenhouse (Experimental Garden Jean Massart, Université Libre de Bruxelles, Belgium). After three months of culture, fresh leaves were collected, immediately immersed into acetone, and stored in this solvent for a maximum of three months. The material was washed three times with acetone and the extraction of PS was performed as previously described [18] with some modifications. Briefly, dried and crushed leaves (17.6 g) were extracted by water $(1 \times 1000 \mathrm{~mL})$ at $50^{\circ} \mathrm{C}$ for three hours and filtered. The extract was concentrated to $20 \mathrm{~mL}$ at $30^{\circ} \mathrm{C}$ under vacuum. The residual crushed leaves were further incubated in water at $100^{\circ} \mathrm{C}(1 \times 1000 \mathrm{~mL})$ and similarly treated. Both extracts were dialyzed (Medicell International Ltd., London, MW 12-1400 Da) against distilled water for $48 \mathrm{~h}$ at $4^{\circ} \mathrm{C}$ and lyophilized to yield extracts designated as PS50 and PS100, respectively; filtration on a Millipore cellulose filter $(0.22 \mu \mathrm{m})$ yielded extracts PS50F and PS100F. These extracts were maintained at $-18^{\circ} \mathrm{C}$. Biological testing of both extracts, before filtration, showed a synergistic effect between IFN- $\gamma$ and PS50 only; this effect was abolished by the filtration step. For structure comparison purposes, the same extraction was performed on Plantago major leaves.

2.2. Fractionation of the PS50 Crude Extract. Two mg of the PS crude extract were dissolved by swelling in $1 \mathrm{~mL}$ of $5 \mathrm{mM}$ $\mathrm{NaCl}(\mathrm{aq})(24 \mathrm{~h})$, sonicating (2 $\mathrm{min})$ and vortexing (1 min) to obtain an homogeneous solution; $25 \mu \mathrm{L}$ of this solution were injected in a HPLC Agilent 1100 system (Hewlett Packard, Waldbronn, Germany) equipped with a Agilent 1100 RID detector, and two polyhydroxymethacrylate gel permeation columns (SHODEX OH-pack SB-804-HQ followed by a $\mathrm{OH}$-pack SB-806 M-HQ, $300 \times 8 \mathrm{~mm}$ i.d.; exclusion limits, 1000 and $20000 \mathrm{kDa}$; Alltech Associates, Deerfield, USA) connected in series with a PWXL $12 \mu \mathrm{m}, 40 \times 6 \mathrm{~mm}$

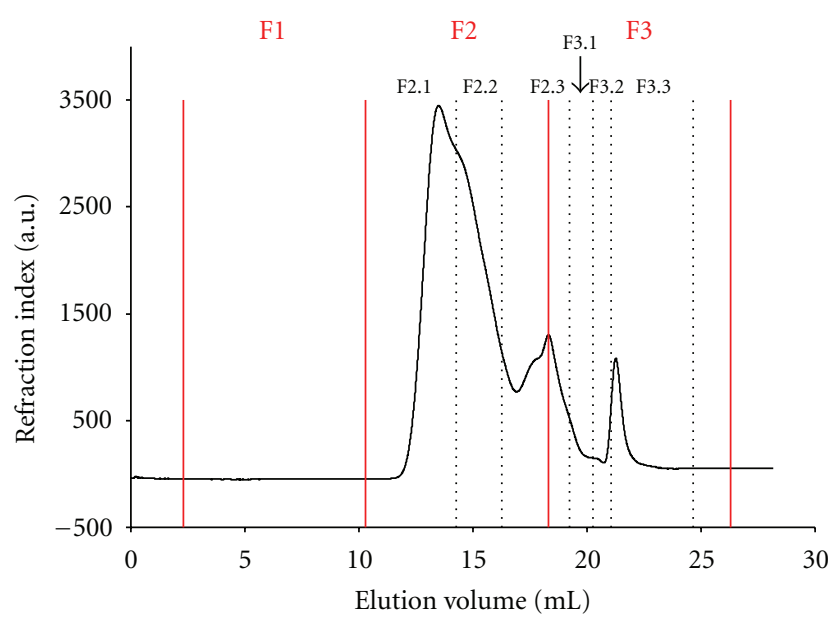

Figure 1: SEC chromatogram of $P$. palmata PS50. Columns, SHODEX OH-pack SB-804-HQ and OH-pack SB-806M-HQ (serially connected; exclusion limits, 1000 and $20000 \mathrm{kDa}$, resp.); mobile phase, $5 \mathrm{mM} \mathrm{NaCl}$ (aq) at $0.8 \mathrm{~mL} / \mathrm{min}$. Three fractions (F1 to F3) and 6 subfractions (F2.1 to F2.3) were collected for biological testing.

i.d. guard column (Tosoh Bioscience, Montgomeryville, USA). The system was driven by a ChemStation A.09.01 software equipped with the GPC add-on A.02.01 (Agilent). The mobile phase was $5 \mathrm{mM} \mathrm{NaCl}$ (aq) at a flow-rate of $0.8 \mathrm{~mL} / \mathrm{min}$. Three fractions and six subfractions were collected according to the elution volume (Figure 1). After four injections, the collected fractions were pooled and dialysed (silver-A-Lyzer, Rockford, USA) at $4^{\circ} \mathrm{C}$ against distilled water for 3 days, renewing the dialysis bath every 24 hours, and dialysates were lyophilized. This size exclusion chromatography yielded a fraction significantly more active than PS50, fraction F2, but the subsequent subfractionations were unsuccessful to concentrate the activity [3].

2.3. Estimation of the Molecular Weights. After a 24 hours equilibration of the size exclusion chromatography (SEC) system with the mobile phase, a series of calibration standards were injected $(5 \mathrm{mg} / \mathrm{mL}$ solutions of pullulan P5, P20, P-100, P-200, P-400, P-800 in the mobile phase; $25 \mu \mathrm{L}$ injection; 2 injections per calibrator), covering a 5.8 to $853 \mathrm{kDa} M_{w}$ range (Shodex standard P-82 kit). The ChemStation GPC add-on A.02.01 (Agilent) was run on recorded chromatograms to establish a calibration curve " $\log \mathrm{M}_{\max }$ versus Elution volume" (fitting with a quadratic function) and the molecular weights of the polymers were estimated as number average molecular weights $\left(M_{n}\right)$, weight average molecular weights $\left(M_{w}\right), Z$ average molecular weights $\left(M_{z}\right)$, and peak molecular weights $\left(M_{p}\right)$.

2.4. Reaction with the Yariv $\beta$-Glucosyl Antigen. $3.5 \mathrm{~mL}$ of an agarose suspension ( $1 \%$ in $0.15 \mathrm{M} \mathrm{NaCl}$ and $0.02 \% \mathrm{w} / \mathrm{v} \mathrm{NaN}$ (aq)) were added with $10 \mu \mathrm{g} / \mathrm{mL}$ (aq) of the Yariv reagent (Biosupplies Australia) and cast on glass plates to form a 1-mm gel. After solidification, 1.2 -mm i.d. wells were dug into the gel and filled with $0.8 \mu \mathrm{L}$ of tested PS solutions 
( 0.1 to $1 \mu \mathrm{g} /$ well). The plates were incubated overnight in a humidified atmosphere and red halos were compared with those obtained from an Arabic gum suspension (Federa, Brussels, Belgium) applied at the same concentrations.

2.5. Determination of the Monosaccharides Composition by HPLC. HPLC was performed upon prechromatographic derivatization with 3-methyl-1-phenyl-2-pyrazolin-5-one (MPP) according to Honda et al. [19]). Each PS (1 mg) or fraction $(200 \mu \mathrm{g})$ was hydrolyzed in $1 \mathrm{~mL} 2 \mathrm{M}$ trifluoroacetic acid (aq) $\left(100^{\circ} \mathrm{C}, 1\right.$ hour), dried under vacuum (SpeedVac) and taken up in 3 portions of $500 \mu \mathrm{L}$ methanol $(30 \mathrm{sec}$ sonication). The combined methanolic solutions were added or not with $10 \mu \mathrm{L}$ of the internal standard (I.S., talose, $1 \mathrm{mg} / \mathrm{mL}(\mathrm{aq})$ ), dried, taken up in $150 \mu \mathrm{L}$ water, and filtered.

Individual solutions of monosaccharides (arabinose, fucose, glucose, galactose, mannose, rhamnose, xylose, glucuronic acid, and galacturonic acid) were dissolved in methanol $(1 \mathrm{mg} / \mathrm{mL})$, mixed in different proportions to prepare calibrators ( 2 to $40 \mu \mathrm{g}$ of each ose), evaporated to dryness and dissolved in $150 \mu \mathrm{L}$ water.

Hydrolyzed polymers or calibrators were added with $20 \mu \mathrm{L}$ of a $0.5 \mathrm{M}$ methanolic solution of 3-methyl-1-phenyl2-pyrazolin-5-one (Acros Organics, New Jersey, USA) and $20 \mu \mathrm{L}$ of $0.3 \mathrm{M} \mathrm{NaOH}(\mathrm{aq})$, incubated $2 \mathrm{~h}$ at $70^{\circ} \mathrm{C}$, neutralized by $20 \mu \mathrm{L} 0.3 \mathrm{M} \mathrm{HCl}(\mathrm{aq})$ and extracted 3 times with $500 \mu \mathrm{L}$ of butyl ether ( $10 \mathrm{~s}$ vortex, $5 \mathrm{~min}$ centrifugation at $2000 \mathrm{rpm}$ ). The aqueous phase was then dried under vacuum (SpeedVac) and redissolved in $150 \mu \mathrm{L}$ water; 10 to $25 \mu \mathrm{L}$ of this solution were injected in a HPLC Agilent 1100 system equipped with a Agilent 1100 DAD detector set at $254 \mathrm{~nm}$ and a $250 \times 4.6 \mathrm{~mm}$ i.d. Atlantis $\mathrm{dC}_{18}$ column (Waters, Ireland). The mobile phases A (triethylamine: acetonitrile: water, $0.4: 10: 90, \mathrm{v} / \mathrm{v}$ ) and B (acetonitrile: water, 60:40, v/v) were pumped at $1 \mathrm{~mL} / \mathrm{min}$ with the following gradient: $0 \mathrm{~min}, 10 \% \mathrm{~B} ; 22 \mathrm{~min}$, $28 \%$ B; $55 \mathrm{~min}, 28 \%$ B; 56 min, 10\% B; 65 min, 10\% B.

2.6. Determination of the Monosaccharide Composition by TLC. Hydrolyzed PS ( $5 \mu \mathrm{g} / \mathrm{spot})$ and standards $(0.5 \mu \mathrm{g} / \mathrm{spot})$ were applied on silicagel $60 \mathrm{~F}_{254}$ plates (Merck, Germany). The plates were eluted with acetonitrile: water $(80: 20)$ (2 developments over $9 \mathrm{~cm}$ with mobile phase renewing), dried, sprayed with a mixture $0.2 \% \mathrm{w} / \mathrm{v}$ naphtoresorcinol in ethanol: $\mathrm{H}_{2} \mathrm{SO}_{4}(96: 4, \mathrm{v}: \mathrm{v})$ and heated at $105^{\circ} \mathrm{C}$ for $15 \mathrm{~min}$.

2.7. Linkage Analysis. Prior to linkage analysis by methylation and GC-MS [20], the uronic acid groups of the PS were reduced. PS50 $(1 \mathrm{mg})$ or its fractions $(200 \mu \mathrm{g})$ were treated by sodium borodeuteride $\left(\mathrm{NaBD}_{4}\right)$ after activation with carbodiimide [21]; the use of borodeuteride allows to differentiate the masses of the reduced uronic acids from the corresponding neutral monosaccharides [22]. The reduced PS were then methylated by methyl iodide and hydrolyzed in 2.5 M TFA (aq) $\left(100^{\circ} \mathrm{C}, 1\right.$ hour). After reduction by $\mathrm{NaBD}_{4}$ and acetylation with acetic anhydride [20], the resulting partially methylated alditol acetates were analyzed by GC-MS (I.S.: inositol) on a Hewlett-Packard methyl silicone capillary column $(12 \mathrm{~m} \times 0.22 \mathrm{~mm}$ i.d., $0.33 \mu \mathrm{m}$ film $)$ in the E.I. ionization mode, as previously described [22].
Methanolysis was performed according to the method of Chambers and Clamp [23] with modifications as previously described [18], using $4 \mathrm{M} \mathrm{HCl}$ in anhydrous methanol for $24 \mathrm{~h}$ at $80^{\circ} \mathrm{C}$; the methyl glycosides were then silylated and analyzed by GC [18].

2.8. Measurement of DNA Contamination. Two mg of the crude PS extract of Plantago major or Plantago palmata were dissolved by swelling overnight at $4^{\circ} \mathrm{C}$ in $8 \mathrm{~mL}$ buffer (10 mM Tris, $0.2 \mathrm{M} \mathrm{NaCl,} 1 \mathrm{mM}$ EDTA (aq), pH 7.4). A series of dilutions of this solution were analyzed with the kit DNA quantitation Hoechst 33258 bisbenzimide (BioRad), following the manufacturer's protocol (reference: calf thymus DNA).

\section{Results and Discussion}

3.1. Harvesting and Extraction. Preliminary extraction trials on Plantago palmata leaves that were dried upon harvesting resulted in a brownish material, heavily contaminated with chlorophyll. Colorless material could not be separated, which may indicate an enzymatic activity during the drying step, probably leading to some covalent bonding. Postharvesting treatment with acetone overcame the problem, removing chlorophyll and other colored low molecular weight lipophilic material and inactivating enzymes, so that white PS fractions could be obtained.

3.2. Fractionation of the PS50 Crude Extract. Figure 1 shows a typical SEC chromatogram obtained for Plantago palmata PS50, indicating the collected fractions; biological data [3] indicate that fraction F2 is the most active one.

Referring to a calibration curve obtained with pullulan standards, the molecular weights of PS50 and PS50F were estimated (Table 1). Three peaks could be discerned from the chromatogram of the active PS50, a very high molecular weight $\left(M_{w}\right.$ about $\left.1200 \mathrm{kDa}\right)$, and 2 lower weight $\left(M_{w}\right.$ about $270 \mathrm{kDa}$ and $12 \mathrm{kDa}$, resp.) polymers.

As there is no obvious difference between the active PS50 and inactive PS50F, these data do not allow explaining the detrimental effect of the filtration step on biological activity [3].

As SEC determinations are not dependent on the molecular mass but on the hydrodynamic volume of the solute [24], these mass values however need confirming by an absolute method based on multiangle laser light scattering. Indeed arabinogalactan-proteins (AGPs) are known for globular structures which may strongly influence the retention on SEC columns [25].

3.3. Reaction with the Yariv $\beta$-Glucosyl Antigen. As arabinogalactans are important immunomodulatory substances, their presence within the polysaccharides has been investigated $[26,27]$. The Yariv $\beta$-glucosyl reagent precipitates some AGPs of vegetal cell walls, especially those with a high proportion of 1,3,6-linked galactose residues [28, 29]. As this reagent presents a still unexplained specificity for polymers with bioactive structures, the formation of a red precipitate 
TABle 1: Molecular weights of polymers obtained from Plantago palmata leaves by aqueous extraction $\left(50^{\circ} \mathrm{C}, 3\right.$ hours $)$, concentration and extensive dialysis (PS50) and further filtration (PS50F) on a Millipore cellulose filter $(0.22 \mu \mathrm{m})$. SEC analysis referring to a calibration curve obtained with pullulan standards $(n=3)$.

\begin{tabular}{lcccccc}
\hline Polymer & $\begin{array}{c}\text { Elution volume } \\
(\mathrm{mL})\end{array}$ & $\begin{array}{c}M_{n} \\
(\mathrm{~g} / \mathrm{mol})\end{array}$ & $\begin{array}{c}M_{w} \\
(\mathrm{~g} / \mathrm{mol})\end{array}$ & $\begin{array}{c}M_{z} \\
(\mathrm{~g} / \mathrm{mol})\end{array}$ & $\begin{array}{c}M_{p} \\
(\mathrm{~g} / \mathrm{mol})\end{array}$ & $\begin{array}{c}\text { Polydispersity } \\
\left(M_{w} / M_{n}\right)\end{array}$ \\
\hline \multirow{3}{*}{ PS50 } & 11.8 to $13.8 \mathrm{~mL}^{\mathrm{a}}$ & $1129867( \pm 39000)$ & $1192500( \pm 51000)$ & $1255767( \pm 65000)$ & $1190167( \pm 37000)$ & 1.05 \\
& 13.8 to $16.8 \mathrm{~mL}^{\mathrm{b}}$ & $222537( \pm 16000)$ & $271913( \pm 12000)$ & $322567( \pm 8000)$ & $303167( \pm 12000)$ \\
& 16.8 to $19.6 \mathrm{~mL}^{\mathrm{c}}$ & $39485( \pm 650)$ & $11818( \pm 720)$ & $14856( \pm 760)$ & $9895( \pm 550)$ & 1.24 \\
\hline \multirow{4}{*}{ PS50F } & 11.8 to $13.8 \mathrm{~mL}$ & $1189650( \pm 9000)$ & $1278550( \pm 14000)$ & $1369650( \pm 20000)$ & $1262000( \pm 13000)$ & 1.07 \\
& 13.8 to $16.8 \mathrm{~mL}$ & $230515( \pm 1000)$ & $277390( \pm 620)$ & $325485( \pm 605)$ & $304600( \pm 6000)$ & 1.20 \\
& 16.8 to $19.6 \mathrm{~mL}$ & $10338( \pm 250)$ & $12860( \pm 720)$ & $16068( \pm 960)$ & $10597( \pm 3300)$ & 1.24 \\
\hline
\end{tabular}

$M_{n}=$ Number average molecular weight; $M_{w}=$ Weight average molecular weight; $M_{z}=Z$ average molecular weight; $M_{p}=$ Peak molecular weight.

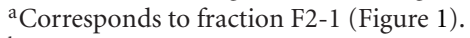

${ }^{\mathrm{b}}$ Corresponds to fraction F2-2 plus part of F2-3 enclosing the tail of the major peak.

${ }^{\mathrm{c}}$ Comprehends the peak skimmed from the major peak (corresponds to the end of fraction F2-3 plus part of F3-1).

TABle 2: Monosaccharides constitutive of the PS extracted from Plantago palmata and Plantago major (\% of total carbohydrates).

\begin{tabular}{lccc}
\hline & & Sample & \\
& PS50 from Plantago major & \\
Man & $5.7 \%(5.8 \%-5.5 \%)$ & PS50 from Plantago palmata $^{\mathrm{a}}$ & Fraction F2 from Plantago palmata $^{\mathrm{b}}$ \\
Ara/Xyl & $27.8 \%(28.8 \%-26.8 \%)$ & $5.4 \%(4.9 \%-6.0 \%)$ & $27.7 \%$ \\
Fuc & Traces & $26.8 \%(25.5 \%-28.0 \%)$ & $17.7 \%$ \\
Glc & $20.7 \%(21.0 \%-20.3 \%)$ & Traces & n.d. \\
Gal & $30.0 \%(30.8 \%-28.7 \%)$ & $39 \%(4.7 \%-4.9 \%)$ & $16.9 \%$ \\
Rha & $7.6 \%(5.6 \%-9.6 \%)$ & $9.6 \%(10.9 \%-8.3 \%)$ & $13.3 \%$ \\
GlcA & Traces & n.d. & $12.5 \%$ \\
GalA & $8.5 \%(8.1 \%-8.8 \%)$ & $14.2 \%(16.5 \%-11.9 \%)$ & n.d. \\
\hline
\end{tabular}

${ }^{a}$ Data from 2 experiments in duplicate; in brackets, the values from the 2 experiments.

${ }^{b}$ Data from 1 experiment in duplicate.

${ }^{\mathrm{c}} \mathrm{TLC}$ shows that the ratio Ara/Xyl is approximately 9: 1 in both Plantago (Figure 4).

is a recognized indication for the presence of bioactive AGPs [30].

As AGPs with immunomodulatory (anticomplementary) activity have been shown in Plantago major [18, 22], we compared its AGPs content with P. palmata (Figure 2). Although the method is only semiquantitative (rapid saturation of the halo with increasing concentrations), it is clear that both Plantago contain AGPs, but with a significantly lower amount in P. palmata.

3.4. Determination of the Monosaccharides Composition. The composition in monomers was determined by HPLC with 3-methyl-1-phenyl-2-pyrazolin-5-one (MPP) prechromatographic derivatization (Figure 3, Table 2). The method was found linear in the investigated range ( 2 to $40 \mu \mathrm{g}$ monomers derivatized, typical $R^{2}>0.990$ with or without I.S.), allowing the determination of neutral monosaccharides and uronic acids in a single step, without the need for acid groups reduction. The resolution was however lower than in GC and we could separate neither rhamnose from the intended internal standard, talose, nor arabinose from xylose. As data computed with or without I.S. were very similar, talose was

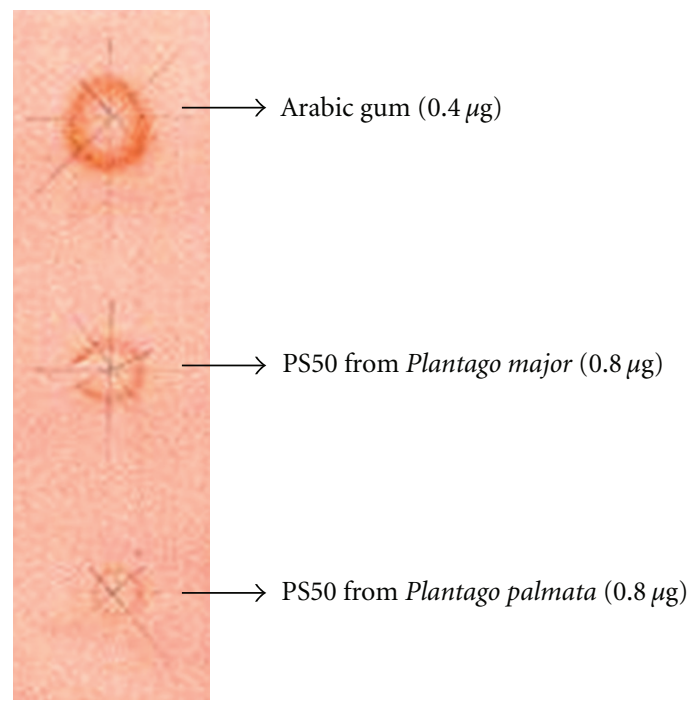

FIGURe 2: Precipitation of the Yariv $\beta$-glucosyl antigen by PS50 extracted from Plantago major or palmata (1\% agarose gel added with $10 \mu \mathrm{g} / \mathrm{mL}$ of the Yariv reagent (aq); $0.8 \mu \mathrm{L} /$ well of tested PS solutions; overnight incubation). 


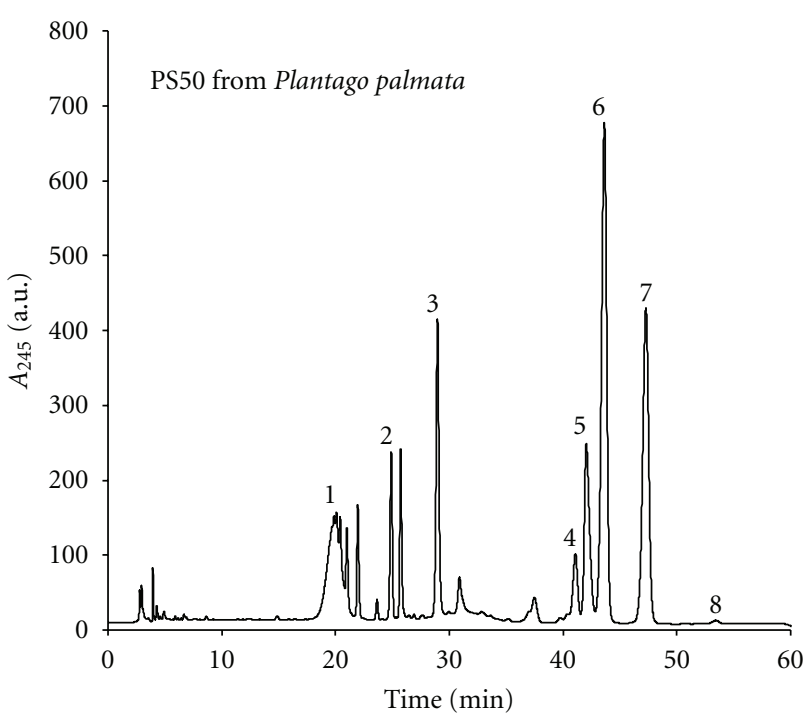

(a)

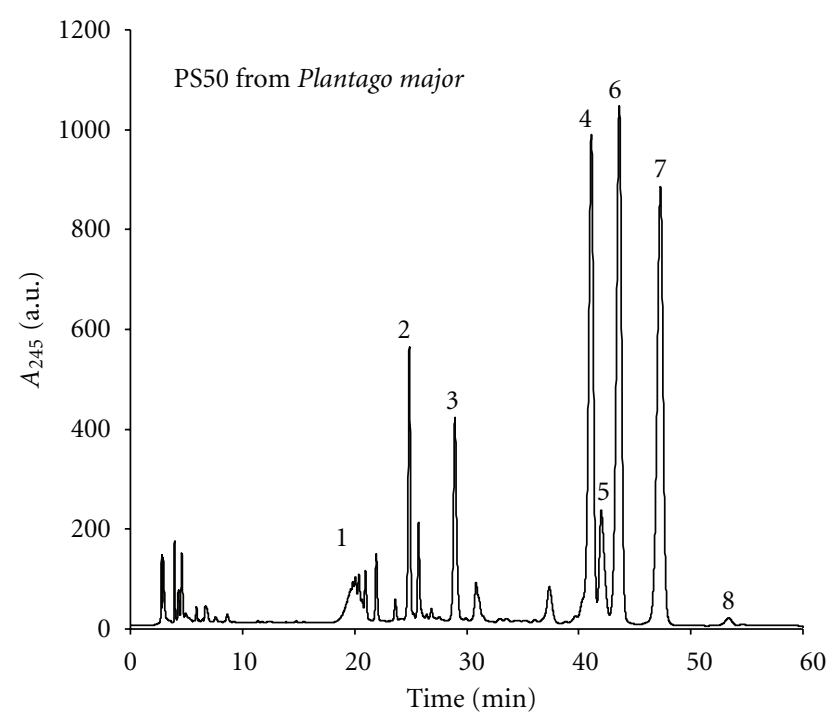

(b)

FIGURE 3: HPLC chromatogram of monosaccharides constitutive of the PS50 extracted from Plantago palmata and Plantago major (Atlantis $\mathrm{dC}_{18}$ column; gradient of mobile phases $\mathrm{A}$ (water: acetonitrile: triethylamine, $90: 10: 0.4, \mathrm{v} / \mathrm{v}$ ) and $\mathrm{B}$ (water: acetonitrile, $40: 60$, v/v)). Peaks: 1, excess MPP reagent; 2, mannose; 3, rhamnose; 4, glucose; 5 , galacturonic acid; 6 , galactose; 7 , xylose + arabinose; 8 , Fucose.

omitted from the analysis. Both pentoses could be readily resolved by TLC (Figure 4) and GC after methanolysis which both showed that the ratio ara/xyl was approximately $9: 1$ in the PS50 from Plantago major and Plantago palmata. Both PS50 had a roughly similar composition, compatible with pectins; there were however some differences and Plantago palmata PS50 showed a different content in glucose and, to a lesser extent, in galactose and galacturonic acid.

3.5. Linkage Analysis. The major linkage is 1,4 -GalA followed by $1,3,6-$ Gal. Three major pectic polysaccharides

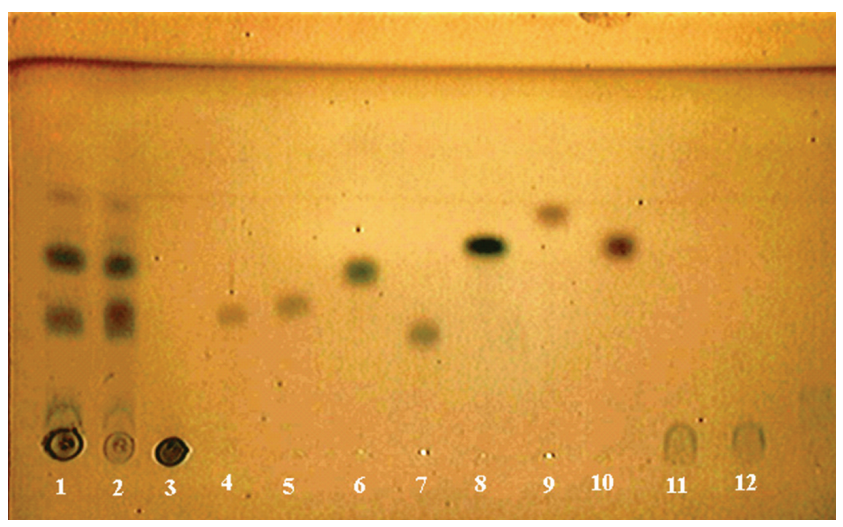

FIGURE 4: TLC chromatogram of monosaccharides constitutive of the PS50 extracted from Plantago palmata and major (silicagel $60 \mathrm{~F}_{254}$, elution with acetonitrile: water $(80: 20)$, revelation with naphtoresorcinol- $\mathrm{H}_{2} \mathrm{SO}_{4}$ ). Lanes: 1, hydrolyzed PS50 from $P$. palmata; 2, hydrolyzed PS50 from P. major; 3, nonhydrolyzed PS50 from $P$. palmata; 4, glucose; 5, mannose; 6, arabinose; 7, galactose; 8 , xylose; 9 , rhamnose; 10 , fucose; 11 , galacturonic acid; 12 , glucuronic acid.

are known to exist in all cell walls, (i) an unbranched homogalacturonan domain (compatible with the observed high ratio of $1,4-$ GalA in PS50); (ii) a highly diversified branched rhamnogalacturonan-I domain with arabinan/galactan/arabinogalactan lateral chains; and (iii) a highly conserved rhamnogalacturonan-II domain [30]. The linkages found (Table 3 ) are typical for homogalacturonan regions (1,4-GalA) and hairy regions of pectins [31]. The rhamnose residues are part of the pectin backbone whereas neutral side chains composed of arabinogalactans, galactans and arabinans are linked to position 4 of the 1,2-linked rhamnose residues. The galactose residues are 1,3-, 1,6-, and 1,3,6-linked while the majority of the arabinose residues are terminally linked indicating the presence of arabinogalactan. The presence of such structures was confirmed by the positive reaction with Yariv antigen. Most of the linkages found in PS50 were also detected in PS50 fraction 2 but could not be quantified due to the small sample size available for analysis.

From previous studies, immunomodulatory activities of pectin polysaccharides seem to depend on the presence of arabinogalactan side chains [32-34]. This might also be the case in the present study, but it remains to confirm this by isolation of pectin hairy regions from Plantago palmata PS50.

The fragmentation by size exclusion chromatography allows to partly resolve the complex and high molecular weight PS fraction but yields only small amounts of polymers, insufficient for complete characterization. The elucidation of structure probably requires additional methods, based on anion exchange chromatography, enzymatic degradation of the polymer and mass spectroscopy of fragments. Such a glycomic approach however still requires major developments, comparatively to genomic and proteomic. Indeed, the many linkages/branching possibilities and the similar $M / Z$ of many of the monomers limit analytical possibilities; moreover the available glycosidases still either lack specificity or are significantly contaminated with undesired activities. 
TABle 3: Products of the PS extracted from Plantago palmata (\% mole) after reduction, methylation, hydrolysis, and acetylation, followed by GC-MS.

\begin{tabular}{|c|c|c|c|}
\hline Monosaccharide & Linkage & $\begin{array}{c}\text { PS50 from } \\
\text { Plantago palmata } \\
(\%)\end{array}$ & $\begin{array}{c}\text { Fraction } 2 \text { from } \\
\text { Plantago palmata } \\
\text { PS50 }\end{array}$ \\
\hline & Terminal & 7.3 & $\mathrm{x}$ \\
\hline & 1,2 & 1.3 & $\mathrm{x}$ \\
\hline \multirow[t]{3}{*}{ Ara $f$} & 1,3 & 1.3 & $\mathrm{x}$ \\
\hline & 1,5 & 0.6 & $\mathrm{x}$ \\
\hline & Total & 10.5 & \\
\hline \multirow[t]{3}{*}{ Fuc $p$} & Terminal & 3.4 & \\
\hline & Terminal & 3.8 & $\mathrm{x}$ \\
\hline & 1,3 & 2.1 & $\mathrm{x}$ \\
\hline \multirow[t]{4}{*}{ Gal } & 1,6 & 5.0 & $\mathrm{x}$ \\
\hline & $1,3,6$ & 13.8 & $\mathrm{x}$ \\
\hline & Total & 24.7 & \\
\hline & Terminal & 1.4 & $\mathrm{x}$ \\
\hline \multirow[t]{4}{*}{ Glc } & 1,4 & 6.3 & $\mathrm{x}$ \\
\hline & Total & 7.7 & \\
\hline & Terminal & 1.5 & \\
\hline & 1,2 & 1.0 & \\
\hline \multirow[t]{4}{*}{ Rha $p$} & 1,3 & 0.4 & $\mathrm{x}$ \\
\hline & $1,2,4$ & 1.1 & \\
\hline & Total & 4.0 & \\
\hline & Terminal & 0.5 & $\mathrm{x}$ \\
\hline \multirow[t]{4}{*}{$\mathrm{Xyl} p$} & 1,4 & 1.4 & \\
\hline & Total & 1.9 & \\
\hline & Terminal & 0.8 & $\mathrm{x}$ \\
\hline & 1,4 & 38.7 & $\mathrm{xx}$ \\
\hline \multirow[t]{3}{*}{ GalA } & $1,3,4$ & 0.5 & \\
\hline & $1,2,4$ & 0.4 & \\
\hline & Total & 40.4 & \\
\hline GlcA & Terminal & 1.9 & $\mathrm{x}$ \\
\hline
\end{tabular}

${ }^{\mathrm{a}} \%$ linkage not quantifiable due to the minute amount of PS analyzed; the $\mathrm{x}$ indicates that the linkage was effectively detected.

3.6. Polysaccharides Contamination by DNA. DNA contaminating hyaluronic acid preparations has been shown to be responsible for the induction of proinflammatory cytokines IL-12 and TNF- $\alpha$ in human monocytes [35]. The DNA contents of Plantago palmata and Plantago major PS50 were $0.04 \pm 0.01 \%$ and $0.08 \pm 0.01 \%$, respectively. These concentrations are much lower than those reported active in hyaluronic acid preparations (3 to 15\%) [35]. This most probably rules out the eventuality of a contaminating DNAmediated biological activity on J774 cells.

\section{Conclusion}

The new polysaccharide with immunomodulatory activities isolated from Plantago palmata has a very high molecular weight $(1200 \mathrm{kDa})$ and is pectic in nature, with a predominantly unbranched galacturonan domain and with a domain bearing side chains that consist of highly branched arabinan, galactan, and/or arabinogalactan. Comparatively to the wellknown Plantago major biologically active polysaccharide (PS), Plantago palmata PS50 contain less arabinogalactanproteins and has different contents of glucose, galactose, and galacturonic acid. It would be interesting to compare the biological activities of both Plantago.

\section{Acknowledgments}

The authors are grateful to Mrs. Helson-Cambier and Mrs. M. Faes for their precious assistance for the chromatographic developments and to Mr. O. Vaillant for maintaining excellent conditions of work in the laboratory.

\section{References}

[1] S. Lisowski, F. Malaisse, and J. J. Symoens, Flore d'Afrique Centrale, Zaire-Rwanda-Burundi, Spermatophytes, Plantaginaceae, Université Nationale du Zaire, Lubumbashi, Jardin Botanique National de Belgique, Bruxelles, Belgium, 1972.

[2] G. Biringanine, M. T. Chiarelli, M. Faes, and P. Duez, "A validation protocol for the HPTLC standardization of herbal products: application to the determination of acteoside in leaves of Plantago palmata Hook. f.s.," Talanta, vol. 69, no. 2, pp. 418-424, 2006.

[3] G. Biringanine, B. Vray, V. Vercruysse, R. Vanhaelen-Fastré, M. Vanhaelen, and P. Duez, "Polysaccharides extracted from the leaves of Plantago palmata Hook.f. Induce nitric oxide and tumor necrosis factor- $\alpha$ production by interferon- $\gamma$-activated macrophages," Nitric Oxide, vol. 12, no. 1, pp. 1-8, 2005.

[4] C. Long, C. Moulis, E. Stanislas, and I. Fouraste, "Aucuboside and catapol in Plantago lanceolata L., Plantago major L., Plantago media L. leaves," Journal de Pharmacie de Belgique, vol. 50, no. 6, pp. 484-488, 1995.

[5] M. D. Bowers, "Variation in iridoid glycosides in a population of Plantago patagonica Jacq. (Plantaginaceae) in Colorado," Biochemical Systematics and Ecology, vol. 24, no. 3, pp. 207210, 1996.

[6] K. Darrow and M. D. Bowers, "Phenological and population variation in iridoid glycosides of Plantago lanceolata (Plantaginaceae)," Biochemical Systematics and Ecology, vol. 25, no. 1, pp. 1-11, 1997.

[7] F. Fons, A. Gargadennec, A. Gueiffier, J. L. Roussel, and C. Andary, "Effects of cinnamic acid on polyphenol production in Plantago lanceolata," Phytochemistry, vol. 49, no. 3, pp. 697702, 1998.

[8] J. Bruneton, Pharmacognosie: Phytochimie. Plantes Médicinales, Tec \& Doc, Paris, France, 1999.

[9] D. H. Paper and M. Marchesan, "Plantain (Plantago lanceolata L.): its introduction, analysis, constituents, pharmacology and standardisation," Zeitschrift fur Phytotherapie, vol. 20, no. 4, pp. 231-238, 1999.

[10] N. Rønsted, E. Göbel, H. Franzyk, S. R. Jensen, and C. E. Olsen, "Chemotaxonomy of Plantago. Iridoid glucosides and caffeoyl phenylethanoid glycosides," Phytochemistry, vol. 55, no. 4, pp. 337-348, 2000.

[11] A. B. Samuelsen, "The traditional uses, chemical constituents and biological activities of Plantago major L. A review," Journal of Ethnopharmacology, vol. 71, no. 1-2, pp. 1-21, 2000.

[12] R. Slaveska-Raicki, V. Rafajlovska, V. Rizova, and I. Spirevska, "HPTLC determination of gallic acid and tannin in extracts of 
bearberry leaves," Journal of Planar Chromatography, vol. 16, no. 5, pp. 396-401, 2003.

[13] R. Li, W. C. Chen, W. P. Wang, W. Y. Tian, and X. G. Zhang, "Extraction, characterization of Astragalus polysaccharides and its immune modulating activities in rats with gastric cancer," Carbohydrate Polymers, vol. 78, no. 4, pp. 738-742, 2009.

[14] M. Zhang, S. W. Cui, P. C. K. Cheung, and Q. Wang, "Antitumor polysaccharides from mushrooms: a review on their isolation process, structural characteristics and antitumor activity," Trends in Food Science and Technology, vol. 18, no. 1, pp. 4-19, 2007.

[15] L. Xia, X. Liu, H. Guo et al., "Partial characterization and immunomodulatory activity of polysaccharides from the stem of Dendrobium officinale (Tiepishihu) in vitro," Journal of Functional Foods, vol. 4, no. 1, pp. 294-301, 2012.

[16] Y. Sun, H. Liang, X. Zhang, H. Tong, and J. Liu, "Structural elucidation and immunological activity of a polysaccharide from the fruiting body of Armillaria mellea," Bioresource Technology, vol. 100, no. 5, pp. 1860-1863, 2009.

[17] Y.-X. Sun and J. F. Kennedy, "Antioxidant activities of different polysaccharide conjugates (CRPs) isolated from the fruiting bodies of Chroogomphis rutilus (Schaeff.: Fr.) O. K. Miller," Carbohydrate Polymers, vol. 82, no. 2, pp. 510-514, 2010.

[18] A. B. Samuelsen, B. S. Paulsen, J. K. Wold, H. Otsuka, H. Yamada, and T. Espevik, "Isolation and partial characterization of biologically active polysaccharides from Plantago major L.," Phytotherapy Research, vol. 9, no. 3, pp. 211-218, 1995.

[19] S. Honda, E. Akao, S. Suzuki, M. Okuda, K. Kakehi, and J. Nakamura, "High-performance liquid chromatography of reducing carbohydrates as strongly ultraviolet-absorbing and electrochemically sensitive 1-phenyl-3-methyl-5-pyrazolone derivatives," Analytical Biochemistry, vol. 180, no. 2, pp. 351357, 1989.

[20] M. J. McConville, S. W. Homans, J. E. Thomas-Oates, A. Dell, and A. Bacic, "Structures of the glycoinositolphospholipids from Leishmania major. A family of novel galactofuranosecontaining glycolipids," Journal of Biological Chemistry, vol. 265, no. 13, pp. 7385-7394, 1990.

[21] J. B. Kim and N. C. Carpita, "Changes in esterification of the uronic acid groups of cell wall polysaccharides during elongation of maize coleoptiles," Plant Physiology, vol. 98, no. 2, pp. 646-653, 1992.

[22] A. B. Samuelsen, B. S. Paulsen, J. K. Wold, S. H. Knutsen, and H. Yamada, "Characterization of a biologically active arabinogalactan from the leaves of Plantago major L.," Carbohydrate Polymers, vol. 35, no. 3-4, pp. 145-153, 1998.

[23] R. E. Chambers and J. R. Clamp, "An assessment of methanolysis and other factors used in the analysis of carbohydratecontaining materials," Biochemical Journal, vol. 125, no. 4, pp. 1009-1018, 1971.

[24] K. Štulík, V. Pacáková, and M. Tichá, "Some potentialities and drawbacks of contemporary size-exclusion chromatography," Journal of Biochemical and Biophysical Methods, vol. 56, no. 13, pp. 1-13, 2003.

[25] L. Picton, I. Bataille, and G. Muller, "Analysis of a complex polysaccharide (gum arabic) by multi-angle laser light scattering coupled on-line to size exclusion chromatography and flow field flow fractionation," Carbohydrate Polymers, vol. 42, no. 1, pp. 23-31, 2000.

[26] P. Ghildyal, T. E. Grønhaug, A. Rusten et al., "Chemical composition and immunological activities of polysaccharides isolated from the malian medicinal plant syzygium guineense,"
Journal of Pharmacognosy and Phytotherapy, vol. 2, no. 6, pp. 76-85, 2010.

[27] M. Peters, M. Kauth, O. Scherner et al., "Arabinogalactan isolated from cowshed dust extract protects mice from allergic airway inflammation and sensitization," Journal of Allergy and Clinical Immunology, vol. 126, no. 3, pp. 648.e4-656.e4, 2010.

[28] M. A. Jermyn and Y. M. Yeow, "A class of lectins present in the tissues of seed plants," Australian Journal of Plant Physiology, vol. 2, pp. 501-531, 1975.

[29] G.-J. van Holst and A. E. Clarke, "Organ-specific arabinogalactan-proteins of Lycopersicon peruvianum (Mill) demonstrated by crossed electrophoresis," Plant Physiology, vol. 80, pp. 786-789, 1986.

[30] T. Bacic, "Herbal arabinogalactan-(proteins): structure, biosynthesis \& biological function in plant. Development and industrial use," in Proceedings of the 51st Annual Congress of the Society for Medicinal Plant Research ("Fascination, Facts, Fucture"), Society for Medicinal Plant Research (Gesellschaft fur Arzneipflanzenforschung-GA), 2003.

[31] F. Voragen, G. Beldman, and H. Schols, "Chemistry and enzymology of pectins," in Advanced Dietary Fibre Technology, B. V. McCleary and L. Prosky, Eds., pp. 379-398, Blackwell Science, London, UK, 2001.

[32] H. Yamada, "Pectic polysaccharides from Chinese herbs: structure and biological activity," Carbohydrate Polymers, vol. 25, no. 4, pp. 269-276, 1994.

[33] X.-S Wang, Y. Zheng, J. Zuo, and J. Fang, "Structural features of an immunoactive acidic arabinogalactan from Centella asiatica," Carbohydrate Polymers, vol. 59, no. 3, pp. 281-288, 2005.

[34] A. B. Samuelsen, B. S. Paulsen, J. K. Wold et al., "Characterization of a biologically active pectin from Plantago major L.," Carbohydrate Polymers, vol. 30, no. 1, pp. 37-44, 1996.

[35] M. C. Filion and N. C. Phillips, "Pro-inflammatory activity of contaminating DNA in hyaluronic acid preparations," Journal of Pharmacy and Pharmacology, vol. 53, no. 4, pp. 555-561, 2001. 


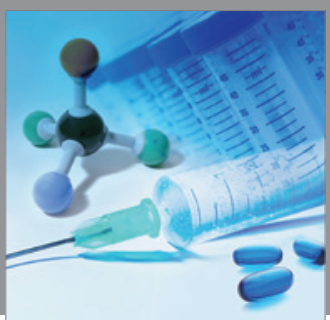

International Journal of

Medicinal Chemistry

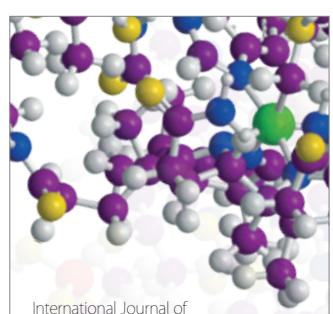

Carbohydrate Chemistry

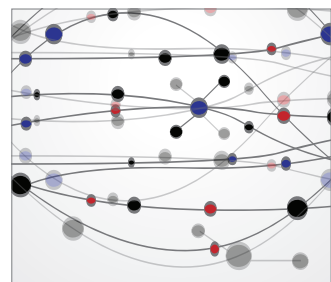

The Scientific World Journal
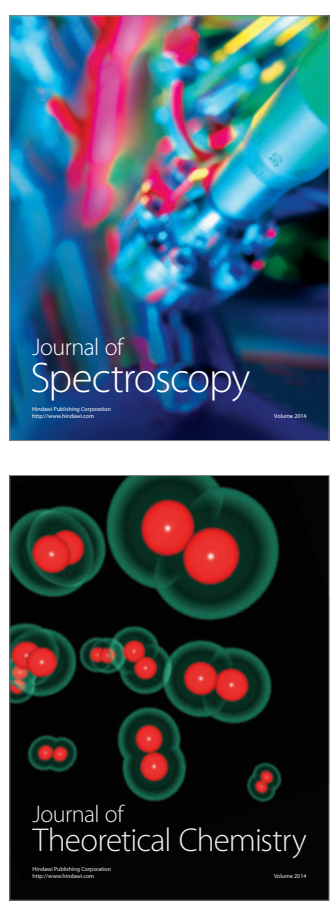
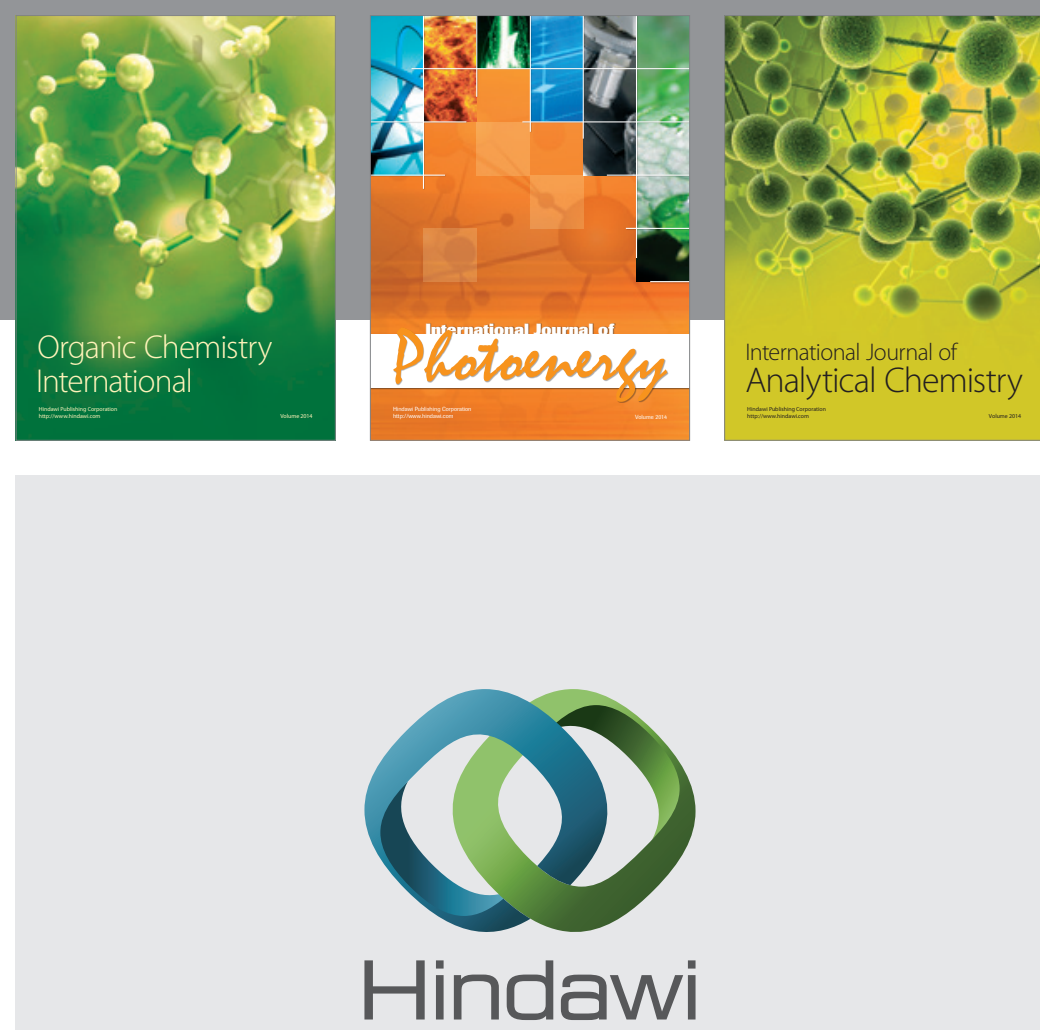

Submit your manuscripts at

http://www.hindawi.com
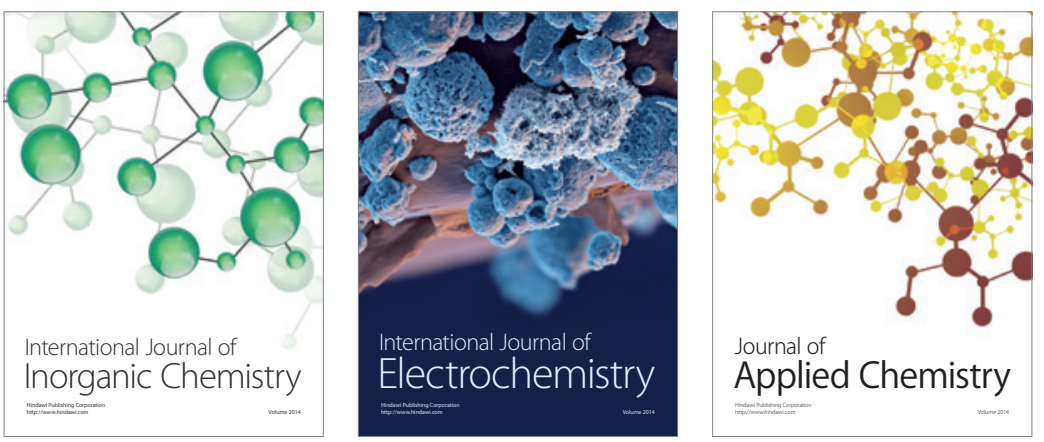

Journal of

Applied Chemistry
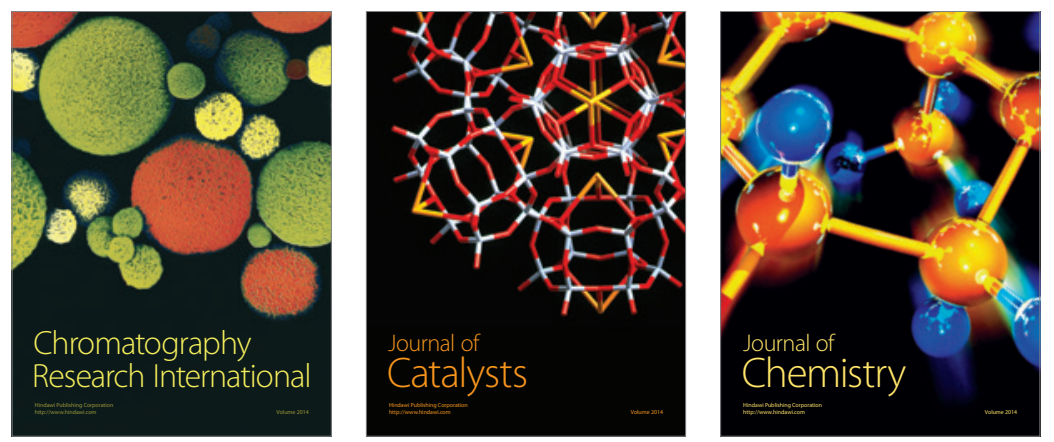
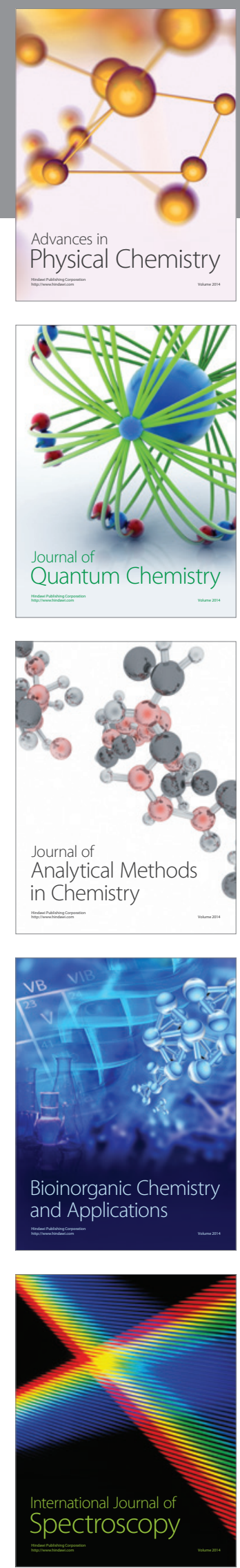